\title{
Attenuated total reflectance infrared spectroelectrochemistry at a carbon particle electrode; unmediated redox control of a [NiFe]-hydrogenase solution $\dagger$
} 15, 7055

Received 10th January 2013,

Accepted 22nd March 2013

DOI: $10.1039 / c 3 c p 00119 a$

\author{
Adam J. Healy, ${ }^{a}$ Philip A. Ash, ${ }^{a}$ Oliver Lenz ${ }^{\mathrm{b}}$ and Kylie A. Vincent ${ }^{\star a}$
}

www.rsc.org/pccp

We report a versatile infrared spectroscopic method for studying redox chemistry of metalloproteins, and demonstrate for the first time electrochemically-induced changes to the active site of the regulatory [NiFe]-hydrogenase from Ralstonia eutropha. A carbon particle network working electrode allows control over a wide potential window without the need for solution mediators.

Hydrogenases are able to oxidise or produce $\mathrm{H}_{2}$ at high turnover frequencies with a low overpotential requirement, and high selectivity for $\mathrm{H}_{2}$ in the face of other gases. ${ }^{1}$ A number of applications of hydrogenases have been explored, including light-driven $\mathrm{H}_{2}$ production, ${ }^{2} \mathrm{H}_{2}$ fuel cells, ${ }^{3}$ and $\mathrm{H}_{2}$-supported recycling of the cofactor $\mathrm{NADH}^{4,5}$ Hydrogenases capable of functioning in the presence of $\mathrm{O}_{2}$ are of particular interest for these applications. This impressive catalytic ability, together with the fact that hydrogenase active sites are built from readily available metals (iron, nickel), has inspired studies directed towards a detailed understanding of their chemistry. The presence of intrinsic $\mathrm{CO}$ and $\mathrm{CN}^{-}$ligands at the active sites means that infrared (IR) spectroscopy is a useful method for following electronic and coordination changes during catalysis or inhibition brought about by light triggers, gas exchange or electrochemical control. ${ }^{6-9}$ Solution IR spectroelectrochemical studies interpreted alongside EPR analysis ${ }^{10}$ and X-ray crystallographic structures have shaped our understanding of hydrogenase structure and mechanism, distinguishing a range of catalytically active and inactive states of the active site, with subtle variations evident between hydrogenases from different organisms. Most of the IR spectroelectrochemical studies on hydrogenases have been

\footnotetext{
${ }^{a}$ Department of Chemistry, University of Oxford, Inorganic Chemistry Laboratory, South Parks Road, Oxford, OX1 3QR, UK. E-mail: kylie.vincent@chem.ox.ac.uk; Fax: +44 (0)1865 272 690; Tel: +44 (0)1865 282611

${ }^{b}$ Department of Chemistry, Technische Universität Berlin, Max-VolmerLaboratorium, Straße des 17. Juni 135, 10623 Berlin, Germany.

E-mail: oliver.lenz@tu-berlin.de; Fax: +49 30314 21122; Tel: +49 3031421433 $†$ Electronic supplementary information (ESI) available: Spectral fitting (Fig. S1); current response during spectroelectrochemical titrations and long-term stability of RH (Fig. S2). See DOI: 10.1039/c3cp00119a
}

carried out in transmission geometry in an optically transparent thin layer electrochemical (OTTLE) cell originally developed by Moss et al. using a gold minigrid working electrode. ${ }^{11}$ It is usually necessary to include small molecule redox mediators to achieve reasonable rates of electron transfer between the electrode and the hydrogenase; an exception is a study of the unusually small $49 \mathrm{kDa}$ [FeFe]-hydrogenase from Chlamydomonas reinhardtii. ${ }^{12}$

An Attenuated Total Reflectance (ATR) geometry opens up more flexible options for choice of working electrode. Rich and co-workers have developed an ATR-IR spectroelectrochemical cell in which a layer of protein coated onto the optical element is in contact with redox which shuttle electrons across the solution interface from a platinum mesh or glassy carbon electrode. ${ }^{13}$ An alternative approach used widely for studying metallic surface chemistry, in which a thin metallic layer deposited on an ATR prism serves as the working electrode, has been adapted for biological molecules. ${ }^{8,14}$ In this configuration, the protein is immobilised onto the gold electrode layer via a self-assembled alkanethiolate monolayer, and is in efficient solute contact, as demonstrated for reduction of hydrogenases upon introduction of $\mathrm{H}_{2}{ }^{8}$

Graphitic electrode materials offer a wide potential window in aqueous solution and are relatively unreactive towards small molecules that are typical substrates or inhibitors of hydrogenases such as $\mathrm{H}_{2}, \mathrm{CO}, \mathrm{CN}^{-}$and $\mathrm{H}_{2} \mathrm{~S} .{ }^{1,15}$ Reduction of $\mathrm{H}^{+}$is negligible at potentials more positive than $-0.8 \mathrm{~V}$ at graphite.

We previously showed that it is possible to record spectra of carboxymyoglobin in a carbon particle film coated onto a $\mathrm{Si}$ ATR prism, using an aqueous Nafion suspension titrated to neutral $\mathrm{pH}$ as a polymer electrolyte and binder. ${ }^{16}$ Here we demonstrate unmediated, electrochemical control of a hydrogenase trapped in a carbon particle film acting as a three-dimensional network electrode. No redox mediators are necessary in our setup because of the short diffusion distances offered by the high surface area carbon particle electrode. For this study, we select the nickel-iron regulatory hydrogenase $(\mathrm{RH})$ from the 'Knallgas' bacterium Ralstonia eutropha. IR studies have shown the active site of the RH to harbour a standard set of diatomic ligands on 


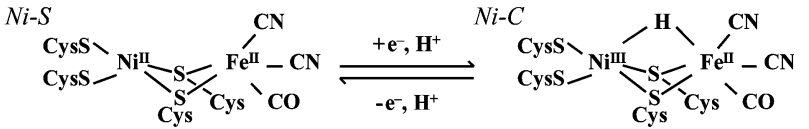

Fig. 1 Interconversion of $\mathrm{RH}$ active site $\mathrm{Ni}-\mathrm{S}$ and $\mathrm{Ni}-\mathrm{C}$ states.

the $\mathrm{Fe},{ }^{17}$ but the enzyme has not been studied under electrochemical control. By contrast to other hydrogenases, only two redox states are sufficiently long-lived to be observed spectroscopically; the as-isolated Ni-S state $\left[\nu(\mathrm{CO}): 1943 \mathrm{~cm}^{-1} ; \nu(\mathrm{CN})\right.$ : $\left.2082,2071 \mathrm{~cm}^{-1}\right]$ and the $\mathrm{H}_{2}$-reduced Ni-C state $\left[\nu(\mathrm{CO}): 1961 \mathrm{~cm}^{-1}\right.$; $\left.\nu(\mathrm{CN}): 2082,2072 \mathrm{~cm}^{-1}\right] \cdot{ }^{18,19}$ The $\mathrm{Ni}-\mathrm{S}$ state is assigned as $\mathrm{Ni}^{\mathrm{II}} / \mathrm{Fe}^{\mathrm{II}}$ and is EPR-silent. ${ }^{17}$ Proton-coupled 1-electron reduction leads to the Ni-C state, which is detectable by EPR and is assigned as $\mathrm{Ni}^{\mathrm{III}} / \mathrm{Fe}^{\mathrm{II}}$ with a bridging $\mathrm{H}^{-}$(Fig. 1). ${ }^{20}$

\section{Experimental}

Ralstonia eutropha $\mathrm{RH}$ was purified according to a published procedure ${ }^{21}$ and concentrated to $10 \mathrm{mg} \mathrm{mL}^{-1}$. Phosphate buffer (pH 6, $50 \mathrm{mM}$ ) was prepared from $\mathrm{K}_{2} \mathrm{HPO}_{4}(\mathrm{BDH})$ and $\mathrm{KH}_{2} \mathrm{PO}_{4}$ (Sigma) with $\mathrm{KCl}$ (Fisher Scientific, $100 \mathrm{mM}$ ) as supporting electrolyte. Stock dispersions of carbon black particles (XC72R, DuPont, $20 \mathrm{mg} \mathrm{mL}^{-1}$ ) were prepared by ultrasonication (5 min) in phosphate buffer. A $1: 1 \mathrm{v} / \mathrm{v}$ mixture of perfluorinated ion exchange resin Nafion ${ }^{\mathbb{R}} 117$ (Aldrich, $10 \%$ dispersion in water, $\mathrm{pH}<2)$ and $\mathrm{K}_{2} \mathrm{HPO}_{4}(100 \mathrm{mM})$ was titrated to the appropriate $\mathrm{pH}$ with concentrated $\mathrm{NaOH}(\mathrm{BDH})$; the resultant mixture contained approximately $5 \% \mathrm{v} / \mathrm{v}$ Nafion ${ }^{\circledR} 117$ and $c a .50 \mathrm{mM}$ phosphate. For the preparation of enzyme-particle mixtures, $2.5 \mu \mathrm{L}$ of this phosphate-buffered Nafion ${ }^{\mathbb{R}}$ was mixed with $20 \mu \mathrm{L}$ of $\mathrm{RH}$ solution and $2.5 \mu \mathrm{L}$ of carbon black particle dispersion and then concentrated by evaporation for $c a .30 \mathrm{~min}$ to a final volume of $c a .15 \mu \mathrm{L}$. Ultra high purity water (MilliQ Millipore, $18 \mathrm{M} \Omega \mathrm{cm}$ ) was used throughout.

Sample preparation was carried out in a $\mathrm{N}_{2}$-filled glove box ( $<1 \mathrm{ppm} \mathrm{O}_{2}$, Glove Box Technology), and spectroscopic measurements were made in a second glove box, linked via a purged antechamber, and maintained under $\mathrm{N}_{2}$ with a dry atmosphere $\left(<-75{ }^{\circ} \mathrm{C}\right.$ dew point). For the ATR-IR measurements a Varian 680-IR spectrometer was placed on a table secured to the rear of the dry glove box, with the IR beam diverted into the glove box via a short purged enclosure and a $5 \mathrm{~mm}$ thick $\mathrm{KBr}$ window. Inside the glove box the IR beam was directed onto an off-axis parabolic focusing mirror and into an ATR accessory (GladiATR, PIKE Technologies). The ATR accessory has been custom-modified to give five reflections at an incidence angle of $39^{\circ}$ through a $\mathrm{Si}$ trapezoidal ATR prism (Crystal GmbH) measuring $8.39 \times 5 \times 1 \mathrm{~mm}^{3}$. After exiting the ATR accessory the IR beam was detected by a narrow-band MCT detector cooled with liquid $\mathrm{N}_{2}$. Spectra were recorded at $2 \mathrm{~cm}^{-1}$ resolution with an acquisition time of either $250 \mathrm{~s}$ or $100 \mathrm{~s}$ for equilibrium or time-course measurements, respectively. For spectroelectrochemical measurements, electrochemical control was provided by an EcoChemie Autolab PGSTAT 128N, and current-time data were collected simultaneously with spectroscopic data.
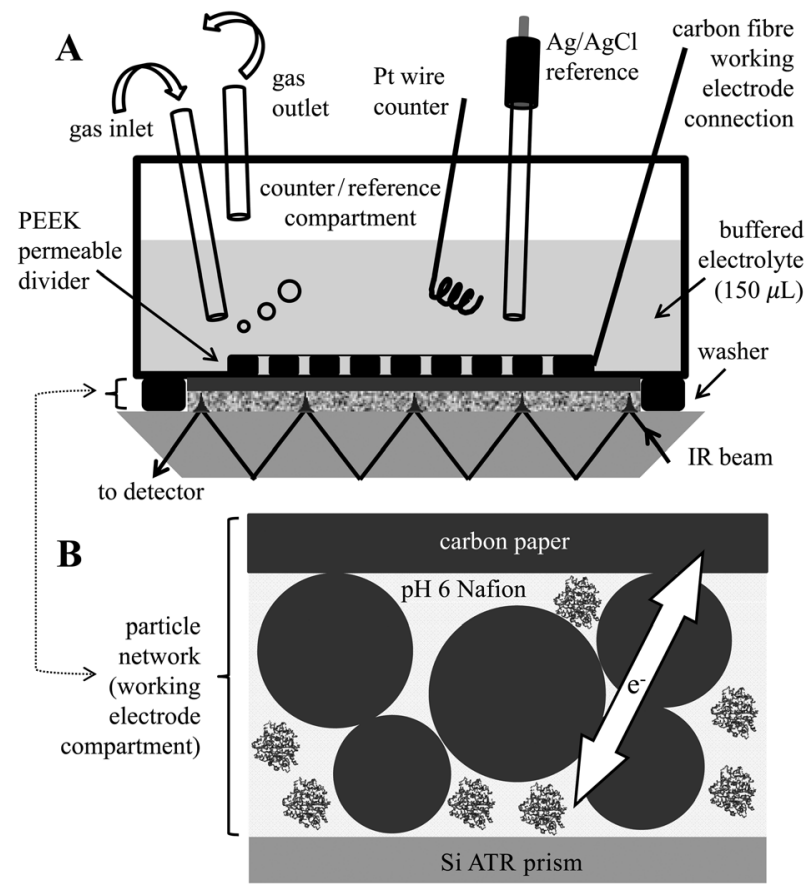

Fig. 2 Panel A: schematic representation of the ATR-IR spectroelectrochemical cell. Panel B: expanded view of particle network working electrode on the Si ATR prism, comprising a mixture of enzyme (ribbons), electronically conducting carbon black particles (dark spheres), phosphate-buffered Nafion and carbon paper backing.

Our ATR-IR spectroelectrochemical cell, based on a preliminary design we have previously described, ${ }^{16}$ was machined from polyether ether ketone (PEEK) and is shown schematically in Fig. 2A, with an expanded view of the particle network working electrode structure in Fig. 2B. To form a particle network working electrode, the concentrated enzyme-particle mixture is applied directly to the prism surface, covering an area approximately $3 \times 6 \mathrm{~mm}^{2}$, and allowed to concentrate further to $c a .3 \mu \mathrm{L}$. The total amount of enzyme in a typical particle network working electrode is $c a .2$ nanomoles. Lateral electrochemical contact is provided by a sheet of carbon paper (AvCarb P50, Ballard Power Systems) placed on top of the Nafionparticle network (Fig. 2B). Electrical contact between this composite working electrode and the cell exterior is made via carbon fibre yarn (Advent Research Materials) incorporated into the cell through a sealed fitting, so that all components of the working electrode are metal-free, based entirely on carbon materials. The cell body is sealed onto the face of the Si ATR prism using a butyl rubber washer, and a PEEK divider, containing an array of $c a .0 .2 \mathrm{~mm}$ diameter channels, is used to separate the counter/reference and working electrode compartments, whilst facilitating efficient electrolyte exchange. The divider also serves to ensure good mechanical contact between the prism, particle network electrode and carbon fibre yarn. A coiled platinum wire (Alfa Aesar, $0.4 \mathrm{~mm}$ diameter) counter electrode is employed alongside a home-built $\mathrm{Ag} / \mathrm{AgCl}$ reference electrode, comprising an electroplated silver wire inserted into a Teflon tube casing filled with $3 \mathrm{M} \mathrm{KCl}$ and stoppered with a 
molecular sieve frit. Potentials (E) are quoted in Volts (V) vs. SHE by calibration against a Saturated Calomel reference electrode (SCE, BAS) using the correction $E(\mathrm{~V} v s$. SHE) = $E$ (V vs. SCE $)+0.241 \mathrm{~V}$ at $25{ }^{\circ} \mathrm{C}$. In situ gas exchange was carried out by bubbling $\mathrm{H}_{2}$ (BOC) into the counter/reference electrode compartment via tubing sealed into the cell. All components of the spectroelectrochemical cell were rinsed thoroughly in MilliQ water between experiments, and the Si ATR prism was cleaned by ultrasonication in concentrated nitric acid (Fisher Scientific). New carbon fibre yarn and carbon paper were used for each experiment and were rinsed in phosphate buffer before use.

\section{Results and discussion}

Fig. 3 illustrates the spectral processing steps involved in the production of an electrochemically triggered difference spectrum of $\mathrm{RH}$ recorded under $\mathrm{N}_{2}$ in our spectroelectrochemical cell. Fig. 3A shows an absolute spectrum of a hydrated particle network electrode containing as-isolated (oxidised) $\mathrm{RH}$ at open circuit potential. Peaks arising from the Nafion binder
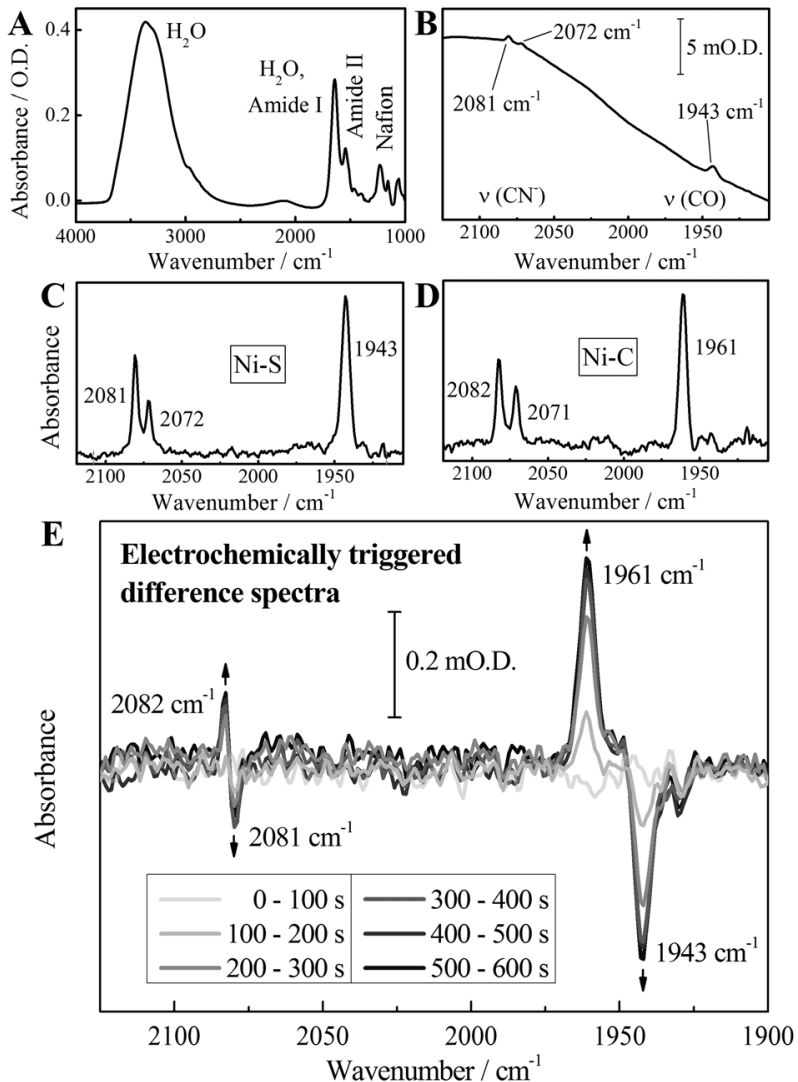

Fig. 3 Panel A: absolute IR spectrum of RH in a particle network electrode at open circuit potential, using a clean prism spectrum as reference. Panel B: expanded view of the intrinsic $\mathrm{CO}$ and $\mathrm{CN}^{-}$ligand stretching region. Panels $\mathrm{C}$ and D: equilibrium IR spectra (250 s acquisition times) following baseline correction of $\mathrm{RH}$ in oxidised $\mathrm{Ni}-\mathrm{S}$ and reduced $\mathrm{Ni}-\mathrm{C}$ states. Panel $\mathrm{E}$ : time course of spectroelectrochemical response of $\mathrm{RH}$ (100 s acquisition time, background recorded at $0 \mathrm{~V}$, potential stepped from $0 \mathrm{~V}$ to $-480 \mathrm{mV}$ at $t=100 \mathrm{~s}$ ). Peak fitting and resulting calculated difference spectra are shown in the ESIt (Fig. S1). appear below $1300 \mathrm{~cm}^{-1}$ and can be attributed to combinations of $\mathrm{CF}_{2}$ and $\mathrm{SO}_{3}{ }^{-}$vibrations, as described elsewhere. ${ }^{22}$ The amide I and amide II bands, at $1652 \mathrm{~cm}^{-1}$ and $1545 \mathrm{~cm}^{-1}$ respectively, are clearly distinguishable, although the amide I band is heavily convoluted with the water bending vibration at $1645 \mathrm{~cm}^{-1}$. Fig. 3B shows an expanded view of the $2125-1900 \mathrm{~cm}^{-1}$ region in which bands arising from CO and $\mathrm{CN}^{-}$ligands of the active site are evident without further spectral processing. These bands appear on a highly curved background due to a broad absorption of liquid water, centred at $c a .2100 \mathrm{~cm}^{-1}$, which is sensitive to changes in $\mathrm{H}$-bonding structure brought about, for example, by changes in solution $\mathrm{pH}$ or an applied potential. ${ }^{23}$ In order to extract quantitative information from absolute spectra it is useful to apply a simple baseline correction in the active site region, to remove the effect of variation in the $2100 \mathrm{~cm}^{-1}$ band. Fig. 3C shows the result of a baseline correction obtained by fitting a cubic spline function to the absolute spectrum shown in Fig. 3A and B at a number of points in the regions $1850-1920 \mathrm{~cm}^{-1}, 1960-2060 \mathrm{~cm}^{-1}$ and 2090-2150 $\mathrm{cm}^{-1}$. These regions were carefully chosen to avoid overlap with any active site bands. A similar procedure was followed to produce a spectrum of a reduced state of $\mathrm{RH}$ following application of $-480 \mathrm{mV} v s$. SHE, shown in Fig. 3D. The observed $\nu(\mathrm{CO})$ and $\nu(\mathrm{CN})$ peak positions in Fig. $3 \mathrm{C}$ and $\mathrm{D}$ are consistent with the presence of $\mathrm{Ni}-\mathrm{S}$ and $\mathrm{Ni}-\mathrm{C}$, respectively. ${ }^{18}$ The time course of conversion between these two states after the potential step is displayed in Fig. 3E, indicating that full conversion is achieved in less than $500 \mathrm{~s}$. This implies efficient diffusion of $\mathrm{RH}$ within the Nafion-particle network. This time course for unmediated electrochemical conversion between states of the hydrogenase is comparable with timescales reported for mediated electron transfer in previous studies. ${ }^{24,25}$ The origin of the small feature at $c a .1930 \mathrm{~cm}^{-1}$ in Fig. $3 \mathrm{E}$ is unclear.

Fig. 4 shows an in situ redox titration of the $\mathrm{RH}$ over a series of reductive steps. Between $-240 \mathrm{mV}$ and $-500 \mathrm{mV}$ spectra were recorded at $20 \mathrm{mV}$ intervals to allow accurate determination of the midpoint potential. Spectral processing was applied as described above, and integrated intensity was calculated as the $\nu(\mathrm{CO})$ peak areas between 1939-1946 $\mathrm{cm}^{-1}$ and 1957-1964 $\mathrm{cm}^{-1}$ for the $\mathrm{Ni}-\mathrm{S}$ and $\mathrm{Ni}-\mathrm{C}$ states, respectively (see inset). No normalisation procedures were performed. Solid lines in Fig. 4 show a fit of these data to the Nernst equation over the potential window $-100 \mathrm{mV}$ to $-600 \mathrm{mV}$, giving a midpoint potential of $-364 \mathrm{mV}$ and $n=1.01$, where $n$ is the number of electrons involved in the transition. A one-electron process is consistent with $\mathrm{Ni}-\mathrm{S}$ to $\mathrm{Ni}-\mathrm{C}$ transitions observed in other hydrogenases. ${ }^{7}$ A similar result is obtained through fitting the $\nu(\mathrm{CN})$ region of the spectrum.

No further changes to spectroscopic features of the hydrogenase were observed at potentials as low as $-1 \mathrm{~V}$, showing that the $\mathrm{RH}$ does not exhibit the fully reduced states, known collectively as $\mathrm{Ni}-\mathrm{R}$, observed in other [NiFe]-hydrogenases. ${ }^{7}$ In the high potential regime, the $\mathrm{Ni}-\mathrm{S}$ state was stable up to $+0.6 \mathrm{~V}$ although irreversible degradation of the active site occurred at more positive potentials. Thus the $\mathrm{RH}$ does not form the oxidised Ni-B state. ${ }^{7}$ For a particle network without 


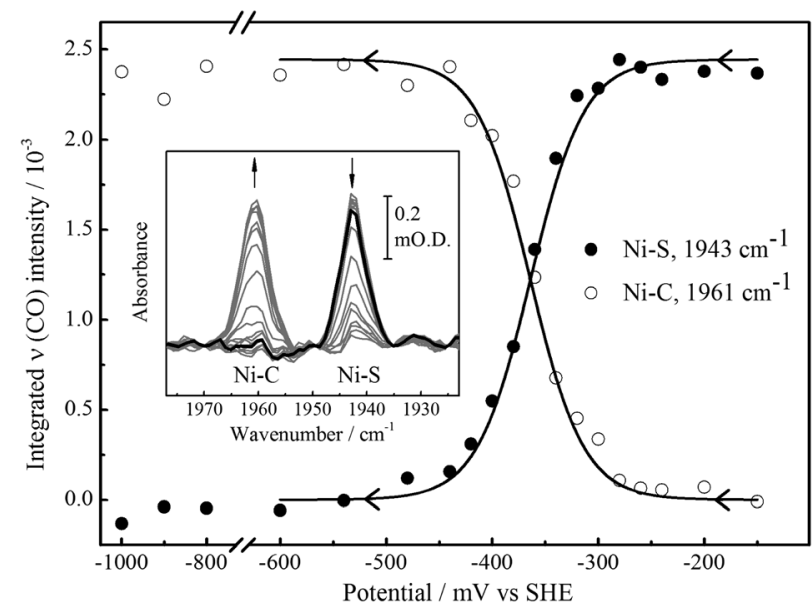

Fig. 4 Infrared spectroelectrochemical redox titration of $\mathrm{RH}$, based upon the integrated intensity of $\nu(\mathrm{CO})$ stretching bands as a function of applied potential (see inset).

hydrogenase, application of potentials up to $+1 \mathrm{~V}$ gave rise to no changes in spectral features in the $2200-1750 \mathrm{~cm}^{-1}$ region. Together, these experiments confirm that a potential window of at least $-1 \mathrm{~V}$ to $+1 \mathrm{~V}$ is accessible at a carbon particle network electrode.

In the presence of $\mathrm{RH}$, significant negative current is observed at potentials below $-480 \mathrm{mV}$ (ESI, $\uparrow$ Fig. S2) where $\mathrm{Ni}-\mathrm{C}$ is the majority species; we attribute this to enzymecatalysed $\mathrm{H}^{+}$reduction since current is negligible in this range in the absence of enzyme. The ability of the $\mathrm{RH}$ to reduce $\mathrm{H}^{+}$ indicates that it remains in an active configuration in the Nafion-particle network. Upon subsequent re-oxidation to the $\mathrm{Ni}-\mathrm{S}$ state the integrated intensity of the active site bands returned to their initial values (not shown), indicating the integrity of the active site over the course of the experiment. The midpoint potential calculated from a redox titration in the reverse direction (from low to high potential) is $-230 \mathrm{mV}$ (ESI, $\dagger$ Fig. S2). We attribute the positive shift of the midpoint potential obtained from the reverse titration to the presence of low levels of $\mathrm{H}_{2}$ produced electrocatalytically by the $\mathrm{RH}$ at low potentials which will re-reduce the electrochemically generated

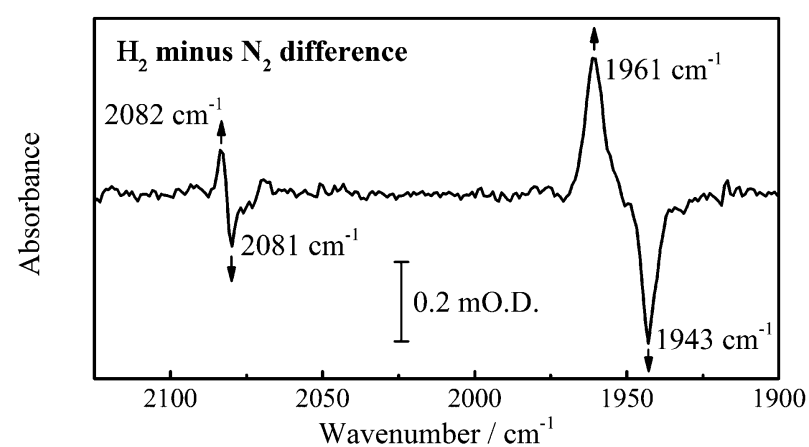

Fig. 5 IR difference spectrum showing the reduction of $\mathrm{RH}$ from $\mathrm{Ni}-\mathrm{S}$ to $\mathrm{Ni}-\mathrm{C}$, triggered by bubbling $\mathrm{H}_{2}$ into the cell electrolyte solution in the absence of applied electrode potential.
$\mathrm{Ni}-\mathrm{S}$ state. The enzyme-loaded particle network used to obtain the data in Fig. 3 was stable over $c a .10$ hours (ESI, $\uparrow$ Fig. S2D).

Fig. 5 shows a difference spectrum triggered by bubbling $\mathrm{H}_{2}$ into the electrolyte solution compartment in the absence of potential control. This demonstrates that diffusion of $\mathrm{H}_{2}$ into the particle network reduces the $\mathrm{Ni}-\mathrm{S}$ state of $\mathrm{RH}$ to $\mathrm{Ni}-\mathrm{C}$, confirming that the enzyme remains catalytically active, and showing the solute access and exchange possible within our experimental cell. The $\mathrm{Ni}-\mathrm{S}$ to $\mathrm{Ni}-\mathrm{C}$ conversion is fully complete within 15 min of commencing $\mathrm{H}_{2}$ bubbling into the cell.

\section{Conclusions}

In this communication we have demonstrated a facile method for studying the response of metalloproteins to a number of external stimuli. The use of a high surface area carbon electrode allows full redox titrations of hydrogenase to be recorded with fine potential resolution, on reasonable timescales and without the need for a cocktail of solution mediators. Construction of the working electrode entirely from carbon allows investigation over a wide potential window and opens up possibilities for studying effects of inhibitors, such as $\mathrm{CO}$ or $\mathrm{CN}^{-}$, which would react with precious metal $\mathrm{Pt}, \mathrm{Au}$, or $\mathrm{Ag}$ electrodes. We have used this method to determine the midpoint potential for interconversion of the active site of $\mathrm{RH}$ between the $\mathrm{Ni}-\mathrm{S}$ and $\mathrm{Ni}-\mathrm{C}$ states. This represents the first spectroelectrochemical study of a hydrogenase over the wide potential window afforded by a carbon electrode.

\section{Acknowledgements}

$\mathrm{AJH}$ is grateful for financial support from the OUP John Fell Fund. KAV is grateful for Fellowship support from the Royal Society, the RCUK and Jesus College Oxford; research of KAV and PAA is supported by ERC Starting Grant 258600. OL thanks Janna Schoknecht for skilful assistance in protein purification and the cluster of excellence 'UniCat' (Deutsche Forschungs-gemeinschaft) for support. Mechanical Workshops (Chemistry, Oxford) are acknowledged for machining the ATR-IR cell. Dr Robert M. J. Jacobs (Chemistry, Oxford) is thanked for assistance with the initial cell design and for helpful discussions.

\section{Notes and references}

1 K. A. Vincent, A. Parkin and F. A. Armstrong, Chem. Rev., 2007, 107, 4366-4413.

2 A. Magnuson, M. Anderlund, O. Johansson, P. Lindblad, R. Lomoth, T. Polivka, S. Ott, K. Stensjö, S. Styring, V. Sundström and L. Hammarström, Acc. Chem. Res., 2009, 42, 1899-1909.

3 A. F. Wait, A. Parkin, G. M. Morley, L. dos Santos and F. A. Armstrong, J. Phys. Chem. C, 2010, 114, 12003-12009.

4 J. Ratzka, L. Lauterbach, O. Lenz and M. B. Ansorge-Schumacher, Biocatal. Biotransform., 2011, 29, 246-252.

5 H. A. Reeve, L. Lauterbach, P. A. Ash, O. Lenz and K. A. Vincent, Chem. Commun., 2012, 48, 1589-1591. 
6 K. A. Bagley, E. C. Duin, W. Roseboom, S. P. J. Albracht and W. H. Woodruff, Biochemistry, 1995, 34, 5527-5535.

7 A. L. De Lacey, V. M. Fernández, M. Rousset and R. Cammack, Chem. Rev., 2007, 107, 4304-4330.

8 D. Millo, M. E. Pandelia, T. Utesch, N. Wisitruangsakul, M. A. Mroginski, W. Lubitz, P. Hildebrandt and I. Zebger, J. Phys. Chem. B, 2009, 113, 15344-15351.

9 M.-E. Pandelia, P. Infossi, M. Stein, M.-T. Giudici-Orticoni and W. Lubitz, Chem. Commun., 2012, 48, 823-825.

10 W. Lubitz, E. Reijerse and M. van Gastel, Chem. Rev., 2007, 107, 4331-4365.

11 D. Moss, E. Nabedryk, J. Breton and W. Mäntele, Eur. J. Biochem., 1990, 187, 565-572.

12 A. Silakov, C. Kamp, E. Reijerse, T. Happe and W. Lubitz, Biochemistry, 2009, 48, 7780-7786.

13 P. R. Rich and M. Iwaki, Mol. Biosyst., 2007, 3, 398-407.

14 K. Ataka and J. Heberle, Biopolymers, 2006, 82, 415-419.

15 P.-P. Liebgott, S. Dementin, C. Léger and M. Rousset, Energy Environ. Sci., 2011, 4, 33-41.

16 A. J. Healy, H. A. Reeve and K. A. Vincent, Faraday Discuss., 2011, 148, 345-357.
17 A. J. Pierik, M. Schmelz, O. Lenz, B. Friedrich and S. P. J. Albracht, FEBS Lett., 1998, 438, 231-235.

18 M. Bernhard, T. Buhrke, B. Bleijlevens, A. L. De Lacey, V. M. Fernández, S. P. J. Albracht and B. Friedrich, J. Biol. Chem., 2001, 276, 15592-15597.

19 T. Buhrke, S. Löscher, O. Lenz, E. Schlodder, I. Zebger, L. K. Andersen, P. Hildebrandt, W. Meyer-Klaucke, H. Dau, B. Friedrich and M. Haumann, J. Biol. Chem., 2005, 280, 19488-19495.

20 M. Brecht, M. van Gastel, T. Buhrke, B. Friedrich and W. Lubitz, J. Am. Chem. Soc., 2003, 125, 13075-13083.

21 T. Buhrke, O. Lenz, N. Krauss and B. Friedrich, J. Biol. Chem., 2005, 280, 23791-23796.

22 A. Gruger, A. Régis, T. Schmatko and P. Colomban, Vib. Spectrosc., 2001, 26, 215-225.

23 J. J. Max and C. Chapados, J. Chem. Phys., 2009, 131, 184505-184513.

24 A. L. deLacey, E. C. Hatchikian, A. Volbeda, M. Frey, J. C. Fontecilla-Camps and V. M. Fernández, J. Am. Chem. Soc., 1997, 119, 7181-7189.

25 M. E. Pandelia, P. Infossi, M. T. Giudici-Orticoni and W. Lubitz, Biochemistry, 2010, 49, 8873-8881. 